\title{
In Situ TiC/FeCrNiCu High-Entropy Alloy Matrix Composites: Reaction Mechanism, Microstructure and Mechanical Properties
}

\author{
Hao Wu ${ }^{1}$ - Si-Rui Huang ${ }^{1} \cdot$ Cheng-Yan Zhu ${ }^{1} \cdot$ Ji-Feng Zhang ${ }^{1} \cdot$ He-Guo Zhu ${ }^{1} \cdot$ Zong-Han Xie ${ }^{2,3}$
}

Received: 7 January 2020 / Revised: 4 May 2020 / Published online: 17 June 2020

(C) The Chinese Society for Metals (CSM) and Springer-Verlag GmbH Germany, part of Springer Nature 2020

\begin{abstract}
In situ $\mathrm{TiC}$ particles-reinforced $\mathrm{FeCrNiCu}$ high-entropy alloy matrix composites were prepared by vacuum induction melting method. The reaction mechanisms of the mixed powder ( $\mathrm{Ti}, \mathrm{Cu}$ and $\mathrm{C}$ ) were analyzed, and the mechanical properties of resultant composites were determined. $\mathrm{Cu}_{4} \mathrm{Ti}$ were formed in the reaction of $\mathrm{Cu}$ and $\mathrm{Ti}$ when the temperature rose to 1160 $\mathrm{K}$. With the temperature further increased to $1182 \mathrm{~K}$, newly formed $\mathrm{Cu}_{4} \mathrm{Ti}$ reacted with $\mathrm{C}$ to give rise to TiC particles as reinforcement agents. The apparent activation energy for these two reactions was calculated to be $578.7 \mathrm{~kJ} / \mathrm{mol}$ and $1443.2 \mathrm{~kJ} /$ mol, respectively. The hardness, tensile yield strength and ultimate tensile strength of the $15 \mathrm{vol} \% \mathrm{TiC} / \mathrm{FeCrNiCu}$ composite are 797.3 HV, 605.1 MPa and 769.2 MPa, respectively, representing an increase by $126.9 \%, 65.9 \%$ and $36.0 \%$ as compared to the $\mathrm{FeCrNiCu}$ high-entropy base alloy at room temperature. However, the elongation-to-failure is reduced from 21.5 to $6.1 \%$ with the formation of $\mathrm{TiC}$ particles. It was revealed that Orowan mechanism, dislocation strengthening and load-bearing effect are key factors responsible for a marked increase in the hardness and strength of the high-entropy alloy matrix composites.
\end{abstract}

Keywords High-entropy alloy matrix composite $\cdot \mathrm{TiC}$ particle $\cdot$ Reaction mechanism $\cdot$ Mechanical properties $\cdot$

Strengthening mechanism

\section{Introduction}

The concept of high-entropy alloys (HEAs) was first introduced in 2004 [1]. Compared with conventional alloys, HEAs contain multiple principal elements with each component having a mole percent of 5-35 [1-3]. Alloys with multiple principal components were previously expected to form complex multi-phase compounds. However, HEAs could consist of simple face-centered cubic (FCC), body-centered

Available online at http://link.springer.com/journal/40195.

He-Guo Zhu

zhg1200@sina.com; zhg1200@njust.edu.cn

$\triangle$ Zong-Han Xie

zonghan.xie@adelaide.edu.au

1 College of Materials Science and Engineering, Nanjing University of Science and Technology, Nanjing 210094, China

2 School of Mechanical Engineering, University of Adelaide, Adelaide, SA 5005, Australia

3 School of Engineering, Edith Cowan University, Joondalup, WA 6027, Australia cubic (BCC) solid solutions or their mixtures [4-6]. Moreover, HEAs have exhibited excellent mechanical properties [7-10], thereby attracting considerable attention in recent years.

The mechanical properties of the HEAs can be further improved by incorporating reinforcing particles such as TiC [11-13], $\mathrm{TiB}_{2}[14,15]$ and $\mathrm{SiC}[16,17]$. For example, $5 \%$ of TiC was added to the $\mathrm{CoCrFeMnNi} \mathrm{high-entropy} \mathrm{alloy} \mathrm{[11].}$ The alloy matrix was refined. At the same time, the compressive strength and tensile strength of the composites were enhanced. In another study, HEA composites prepared by adding 5\% SiC nano-particles [16] also showed the improvement on corrosion resistance and hardness in comparison to the base alloy.

High-entropy alloy matrix composites can be generally divided into two types according to how reinforcements are introduced, namely ex-situ and in situ. It is difficult to control the distribution uniformity of reinforcement particles in the matrix using ex-situ methods. In addition, the interface between the reinforcing particles introduced ex-situ and the matrix is often contaminated and unstable due to poor compatibility between them $[18,19]$. In comparison, the in situ technique involves the reaction of well mixed elements under 
controlled conditions, and the mechanical properties of the resulting composites are improved by a uniform distribution of reinforcing particles. Moreover, the interface between the reinforcing particles and the alloy matrix is stable, due to enhanced compatibility between the reinforcing particles and the alloy matrix.

$\mathrm{FeCrNiCu}$ high-entropy alloy matrix has a single FCC crystal structure with excellent plasticity but mediocre strength. To enhance the strength of this alloy, the $\mathrm{FeCrNiCu}$ alloy was prepared by incorporating $\mathrm{TiC}$ particles into the system. The reaction mechanism was analyzed. The microstructure of the composites was determined. In addition, the strengthening mechanisms of the composites were identified and their contributions to the strength increase were quantified.

\section{Experimental}

\subsection{Material Processing}

Carbon powders (1-5 $\mu \mathrm{m}$ in diameter), titanium powders (30-50 $\mu \mathrm{m}$ in diameter), copper powders $(30-50 \mu \mathrm{m}$ in diameter), iron particles (1-2 $\mathrm{mm}$ in diameter and $4 \mathrm{~mm}$ in length), nickel particles (1-2 $\mathrm{mm}$ in diameter and $4 \mathrm{~mm}$ in length) and chromium particle (1-2 $\mathrm{mm}$ in diameter and 4 $\mathrm{mm}$ in length) were used as raw materials, with the purity of $99.9 \%$ for each. Three types of composite with different volume fractions (5-15 vol\%) of $\mathrm{TiC}$ reinforcements were prepared.

The mixed powders ( $\mathrm{Ti}, \mathrm{Cu}$ and $\mathrm{C}$ ) were placed in a vacuum stainless jar, followed by eight hours of ball milling before being compressed into precast green compacts under the pressure of $150 \mathrm{MPa}$. The precast green compacts and other element particles ( $\mathrm{Fe}, \mathrm{Cr}$ and $\mathrm{Ni}$ ) were then placed in a ceramic crucible surrounded by the induction coil prior to vacuum inductive melting. The mechanical and molecular pumps were used to make the vacuum level down to $5 \times 10^{-3} \mathrm{~Pa}$. The current was set to be $550 \mathrm{~A}$, and magnetic stirring was carried out for $5 \mathrm{~min}$ before the molten metal was poured into a copper crucible and cooled to room temperature. The procedure of samples preparation is presented in Fig. 1.

In order to compare the microstructure and mechanical properties of in situ and ex-situ composites, ex-situ $15 \mathrm{vol} \%$ $\mathrm{TiC} / \mathrm{FeCrNiCu}$ high-entropy alloy matrix composites were fabricated from the powder mixture of TiC, iron, chromium, nickel and copper using vacuum induction melting.

\subsection{Microstructure Characterization}

The X-ray diffraction with $\mathrm{Cu}$ - $K \alpha$ was used to identify the phase constituents in the composites. The diffraction angle

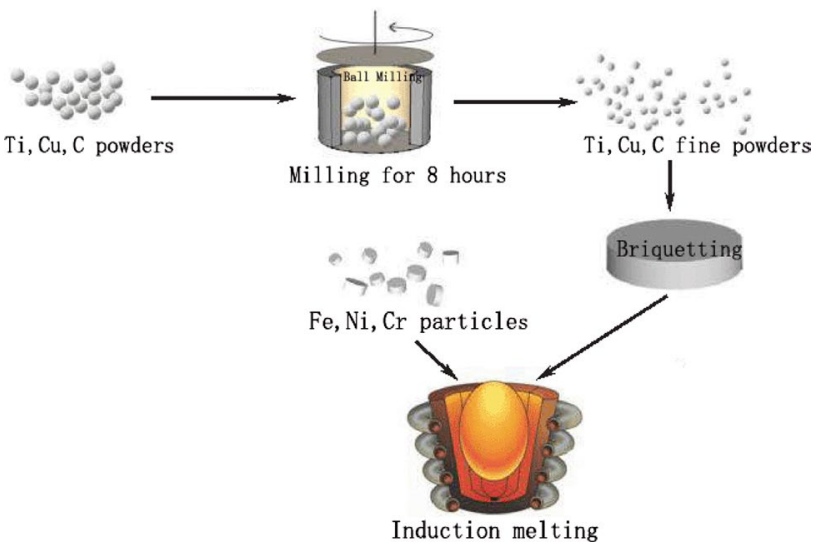

Fig. 1 Schematic diagram of sample preparation process using vacuum inductive current melting

$(2 \theta)$ was in the range of $20^{\circ}-90^{\circ}$ and the scanning speed was set to be $4 \% \mathrm{~min}$. The operating voltage of the scanning electron microscope is $30 \mathrm{kV}$, and the element composition of the samples was analyzed by energy-dispersive spectroscopy (EDS). The detailed microstructure of the samples was examined by transmission electron microscopy (TEM) under the operating voltage of $200 \mathrm{kV}$. Image-Pro plus 6.0 software was used to estimate the size and volume fraction of TiC reinforcements based on the scanning electron microscope images obtained at $3000 \times$ magnification. At least three scanning electron microscopy (SEM) images were examined for each sample.

\subsection{Differential Scanning Calorimetry (DSC) Analysis}

The green compact sample (with a mass about $10 \mathrm{mg}$ ) was placed in a thermal analyzer (DSC, STA449C). The sample was heated from room temperature $(293 \mathrm{~K})$ to $1373 \mathrm{~K}$ in argon atmosphere at four different heating rates (i.e., 15, 20,25 and $30 \mathrm{~K} / \mathrm{min}$ ). The activation energy of the reactions was determined.

\subsection{Mechanical Properties}

The Vickers hardness tests were carried out under the maximum load of $5 \mathrm{~N}$. The hardness values were obtained from the measurements undertaken in five different regions. The samples for the tensile tests (length $\sim 10.6 \mathrm{~mm}$; width $\sim 2.4$ $\mathrm{mm}$; and thickness $\sim 1.2 \mathrm{~mm}$ ) were wire cut from ingots. The tensile tests were conducted using an UTM/CMT 5000 electronic universal testing machine under a strain rate of $0.5 \mathrm{~mm} / \mathrm{min}$ at room temperature. The elongations of the samples were measured by an extensometer. Fracture surfaces were examined using SEM to determine the fracture mechanisms. 


\section{Results and Discussion}

\subsection{Thermodynamic Analysis}

For the powder mixture of $\mathrm{Ti}, \mathrm{C}$ and $\mathrm{Cu}$, the following reactions might take place [20]:

Reaction 1: $\quad \frac{1}{2} \mathrm{Ti}+\frac{1}{2} \mathrm{C} \rightarrow \frac{1}{2} \mathrm{TiC} \quad \Delta G_{1}^{0}=-92400+6.275 T \mathrm{~J} / \mathrm{mol}$.

\subsection{Reaction Mechanisms}

Figure 3a shows the DSC curve of the $\mathrm{Ti}-\mathrm{Cu}-\mathrm{C}$ system obtained at a heating rate of $20 \mathrm{~K} / \mathrm{min}$ in argon gas. There are exothermic peaks at $1160 \mathrm{~K}$ and $1182 \mathrm{~K}$, indicative of two exothermic reaction steps. The endothermic peak at $1359 \mathrm{~K}$ corresponds to the melting process of $\mathrm{Cu}(1356 \mathrm{~K})$, while the exothermic peak at $1337 \mathrm{~K}$ arose from solidification [22]. Comparing to the DSC curve of the $\mathrm{Cu}-\mathrm{Ti}$ sys-

Reaction 2: $\quad \frac{2}{3} \mathrm{Ti}+\frac{1}{3} \mathrm{Cu} \rightarrow \frac{1}{3} \mathrm{Ti}_{2} \mathrm{Cu} \quad \Delta G_{2}^{0}=-12131+4.688 T \mathrm{~J} / \mathrm{mol}$.

Reaction 3: $\quad \frac{1}{2} \mathrm{Ti}+\frac{1}{2} \mathrm{Cu} \rightarrow \frac{1}{2} \mathrm{TiCu} \quad \Delta G_{3}^{0}=-11206+3.272 T \mathrm{~J} / \mathrm{mol}$.

Reaction 4: $\quad \frac{3}{7} \mathrm{Ti}+\frac{4}{7} \mathrm{Cu} \rightarrow \frac{1}{7} \mathrm{Ti}_{3} \mathrm{Cu}_{4} \quad \Delta G_{4}^{0}=-9748+2.278 T \mathrm{~J} / \mathrm{mol}$.

Reaction 5: $\quad \frac{1}{5} \mathrm{Ti}+\frac{4}{5} \mathrm{Cu} \rightarrow \frac{1}{5} \mathrm{TiCu}_{4} \quad \Delta G_{5}^{0}=-6011+2.339 T \mathrm{~J} / \mathrm{mol}$.

To predict the direction and final products of a reaction, the standard Gibbs free energy $\Delta G^{0}$ was calculated by feeding thermodynamic data into Eqs. (1)-(5) [21]. Figure 2 shows that the standard Gibbs free energy change is negative for all the five reactions, meaning that the above reactions are all possible. However, it is worth noting that in the case of Eq. (1) the free energy change is the lowest among the five reactions. Therefore, it can be inferred that $\mathrm{TiC}$ is the most possible reaction product for the $\mathrm{Ti}-\mathrm{Cu}-\mathrm{C}$ system.

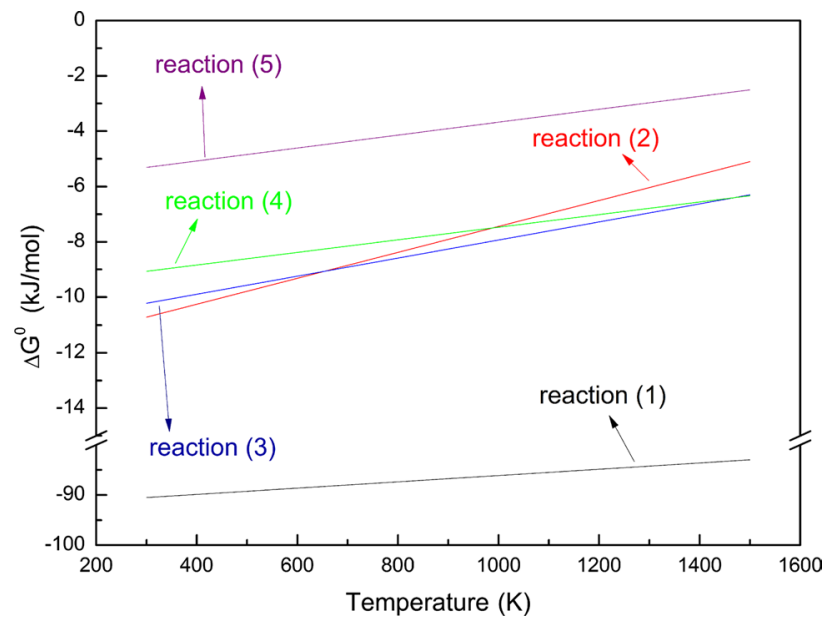

Fig. 2 Gibbs free energy of the reactions as a function of temperature for the $\mathrm{Ti}-\mathrm{Cu}-\mathrm{C}$ system tem obtained at a heating rate of $20 \mathrm{~K} / \mathrm{min}$ (Fig. 3b) and also assisted by the study of $\mathrm{Yu}$ et al. [22], inferring that the exothermic peak of $1160 \mathrm{~K}$ in Fig. 3a stemmed from $\mathrm{Ti}+\mathrm{Cu} \rightarrow \mathrm{Cu}_{4} \mathrm{Ti}$. In order to verify the first step reaction, the samples were heated to $1171 \mathrm{~K}$ and subsequently analyzed with XRD, SEM and EDS. $\mathrm{Cu}$ and $\mathrm{Cu}_{4}$ Ti were identified from the corresponding XRD pattern shown in Fig. 3c. The microstructure and EDS spectrum of reaction products can be seen in Fig. 3d, which confirms the formation of $\mathrm{Cu}_{4} \mathrm{Ti}$ when the temperature increased to about $1160 \mathrm{~K}$.

The exothermic peak ( $1182 \mathrm{~K}$ in Fig. 3a) represents the formation of TiC. Figure $3 \mathrm{e}$ shows the XRD diffraction pattern of the sample prepared from heating up to $1373 \mathrm{~K}$, in which only the diffraction peaks of $\mathrm{Cu}$ and $\mathrm{TiC}$ can be seen. The EDS spectrum of the gray region indicates the existence of $\mathrm{Cu}$, while the dark region is composed of $\mathrm{Ti}$ and $\mathrm{C}$, suggesting the formation of TiC. Therefore, $\mathrm{Cu}_{4} \mathrm{Ti}$ exists only as the transition phase [23]. The reaction process taking place in the $\mathrm{Ti}-\mathrm{Cu}-\mathrm{C}$ system can thus be summarized as follows (Fig. 4):

Step 1: $\quad 4 \mathrm{Cu}+\mathrm{Ti} \rightarrow \mathrm{Cu}_{4} \mathrm{Ti}$.

Step 2: $\mathrm{Cu}_{4} \mathrm{Ti}+\mathrm{C} \rightarrow 4 \mathrm{Cu}+\mathrm{TiC}$. 


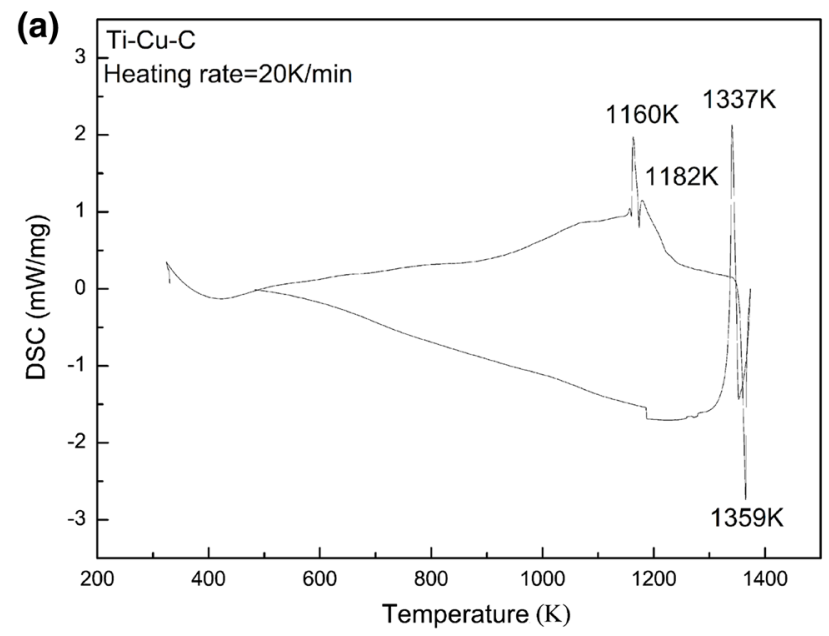

(c)

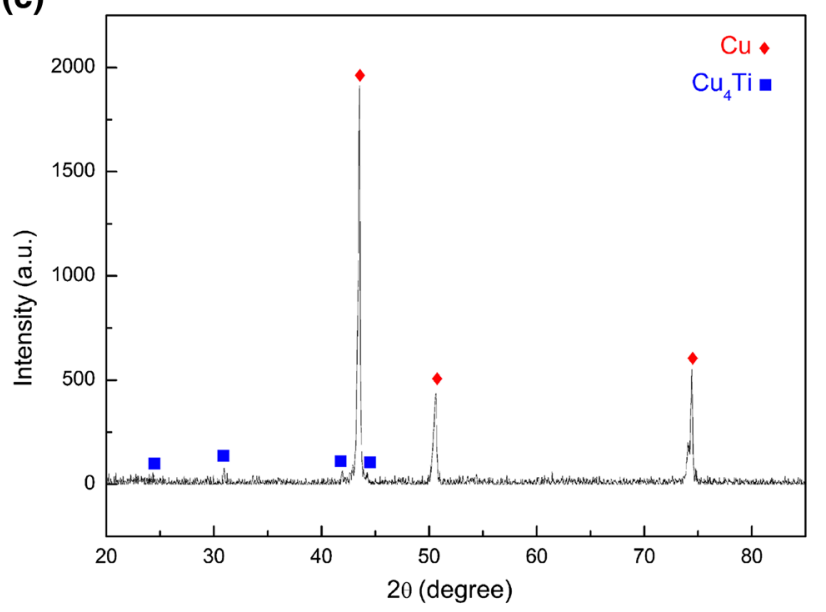

(e)

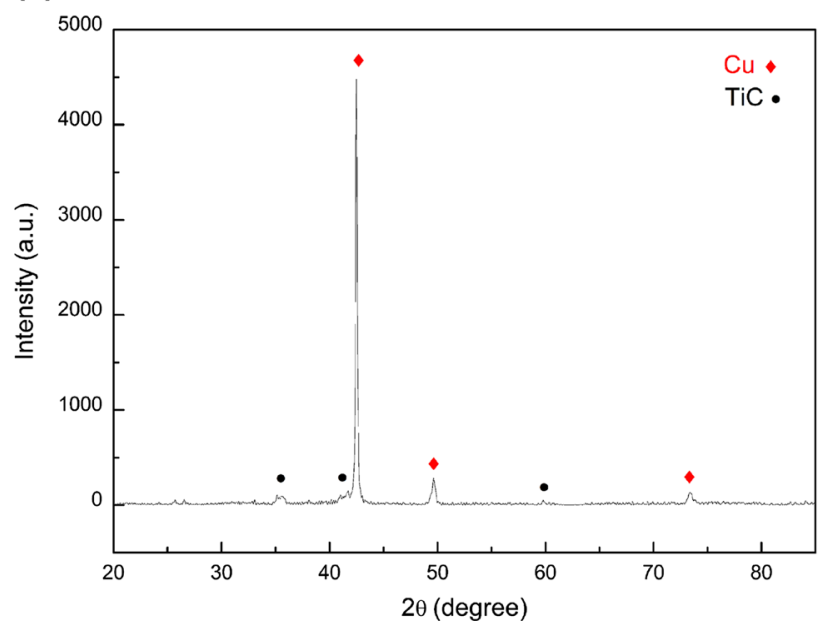

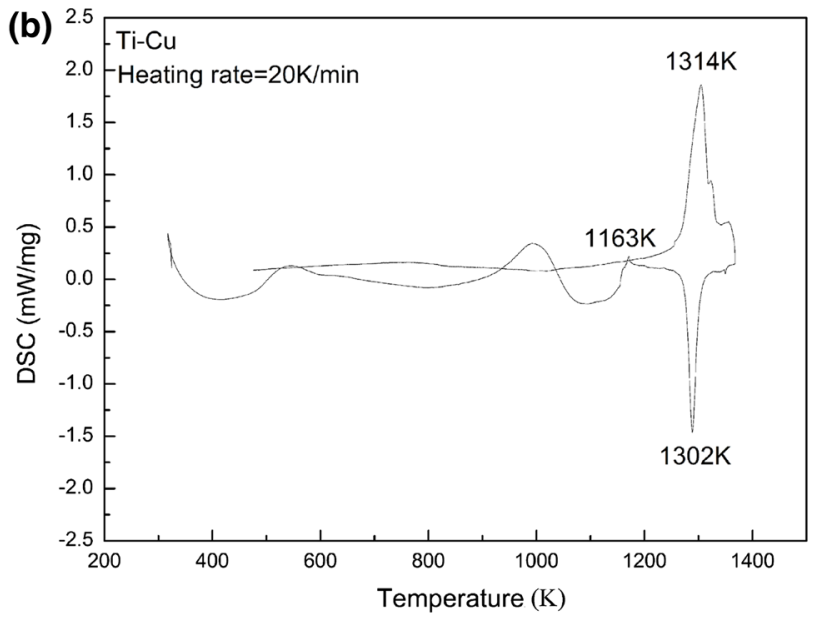

(d)
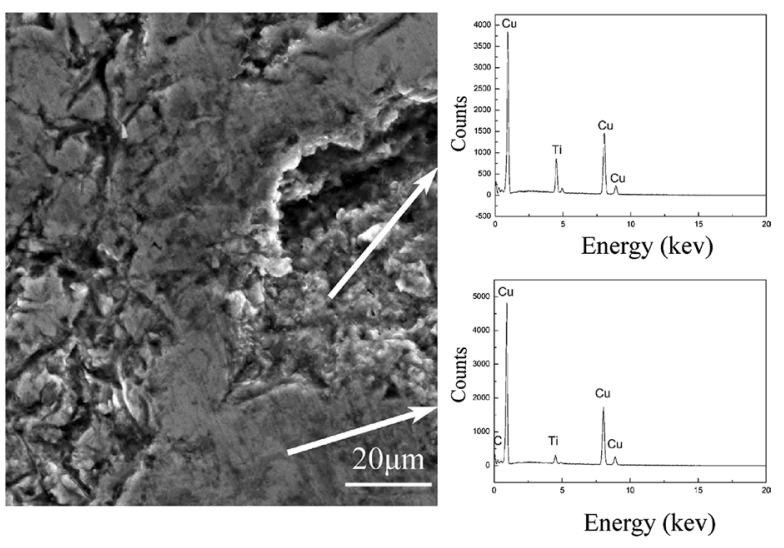

(f)
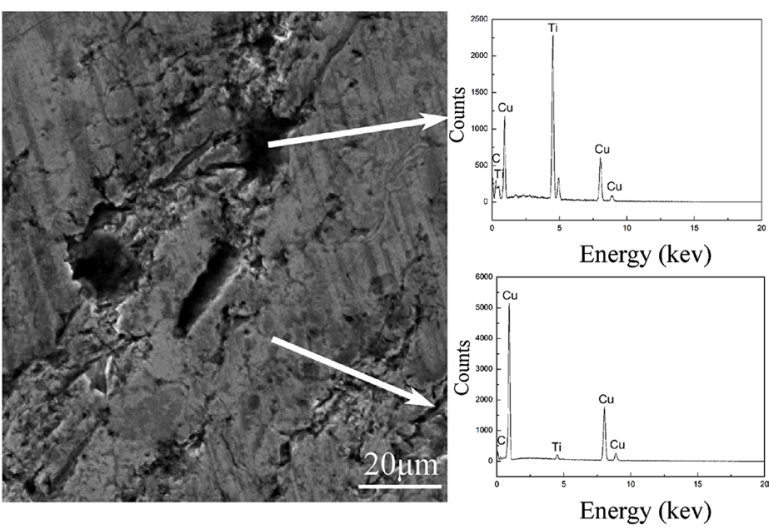

Fig. 3 a DSC curve of Ti-Cu-C system; b DSC curve of Ti-Cu system; $\mathbf{c}$ XRD diffraction pattern of Ti-Cu-C system heated to $1171 \mathrm{~K}$; $\mathbf{d}$ SEM image of $\mathrm{Ti}-\mathrm{Cu}-\mathrm{C}$ system heated to $1171 \mathrm{~K}$; e XRD diffraction pattern of $\mathrm{Ti}-\mathrm{Cu}-\mathrm{C}$ system heated to $1373 \mathrm{~K}$; $\mathbf{f} \mathrm{SEM}$ image of Ti-Cu-C system heated to $1373 \mathrm{~K}$ 


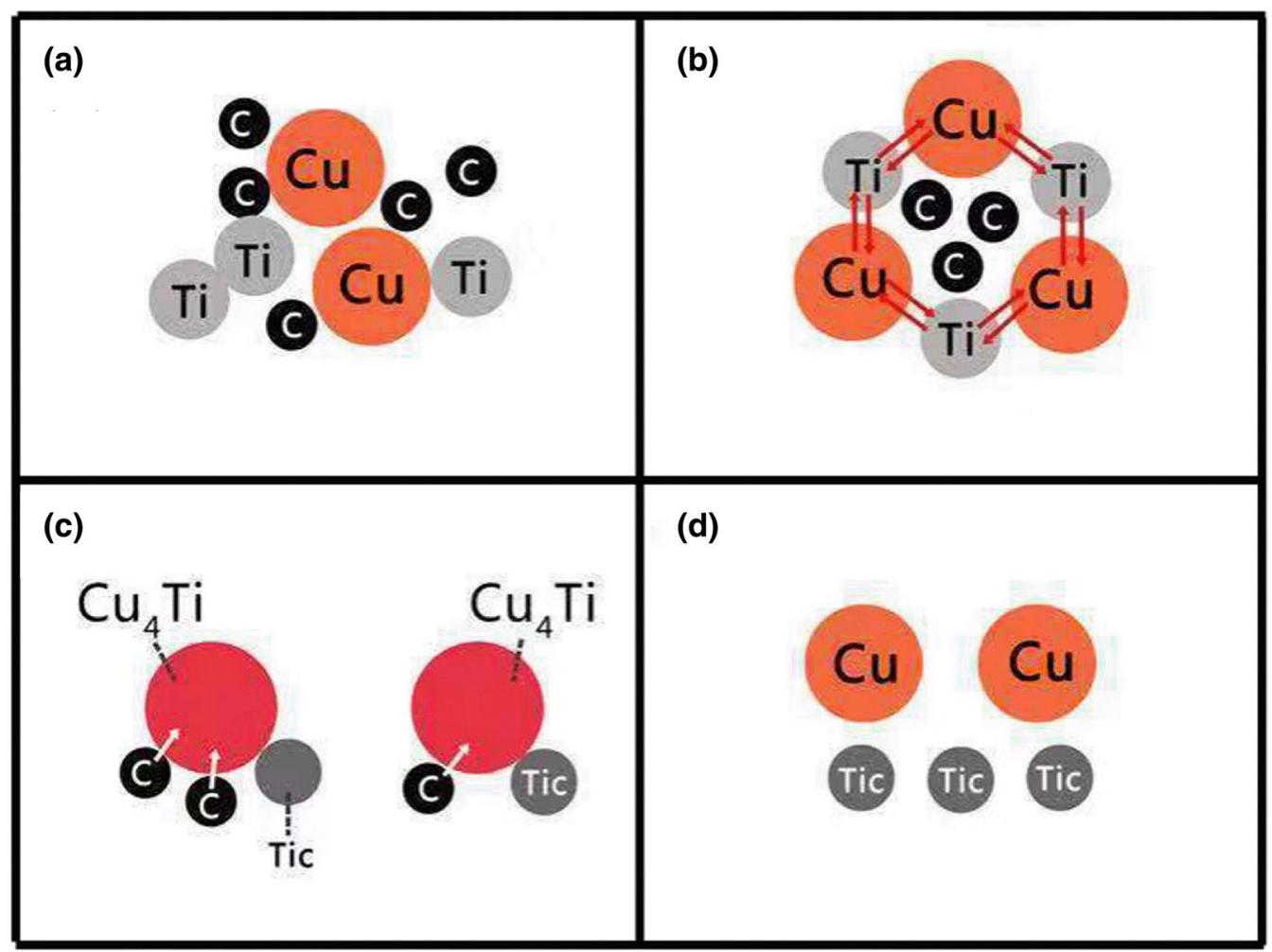

Fig. 4 Schematic diagram of reaction process in the $\mathrm{Ti}-\mathrm{Cu}-\mathrm{C}$ system

\subsection{Calculation of Reaction Activation Energy}

Taking 10 vol\% $\mathrm{TiC} / \mathrm{FeCrNiCu}$ as an example, Fig. 5 shows the DSC curve obtained at the heating rates of 15, 20, 25 and $30 \mathrm{~K} / \mathrm{min}$, respectively. As the heating rate increases, the reaction peak becomes sharper and the reaction temperature moves upward. Based on Kissinger's equation [24], the activation energy of a reaction can be calculated as follows:

$\frac{\mathrm{d}\left(\ln \frac{\beta}{T_{\mathrm{m}}^{2}}\right)}{\mathrm{d}\left(\frac{1}{T_{\mathrm{m}}}\right)}=-\frac{E}{R}$,

where $T_{\mathrm{m}}$ is the temperature of the reaction peak, $\beta$ is the rate of heating, $E$ is the activation energy of the reaction and $R$ is the ideal gas constant (i.e., $8.31 \mathrm{~J} / \mathrm{mol}$ ). The peak temperature of the two reactions at different heating rates (i.e., 15, $20,25,30 \mathrm{~K} / \mathrm{min}$ ) can be obtained from Fig. 5. The values of $1 / T_{\mathrm{m}}$ and $\ln \left(\beta / T_{\mathrm{m}}^{2}\right)$ can then be determined. The relationship between $\ln \left(\beta / T^{2}{ }_{\mathrm{m}}\right)$ and $1 / T_{\mathrm{m}}$ can be fitted linearly and the slope values are $-6.9637 \times 10^{4}$ and $-17.3671 \times 10^{4}$ for two reaction steps expressed in Fig. 6. The activation energies are thus calculated and found to be $578.7 \mathrm{~kJ} / \mathrm{mol}$ and 1443.2 $\mathrm{kJ} / \mathrm{mol}$, respectively. The results show that forming $\mathrm{TiC}$ is difficult (at about $1182 \mathrm{~K}$ ), and the reaction requires a large amount of energy input.

\subsection{Microstructural Characteristics}

Figure 7 shows the XRD diffraction pattern of the composites with different volume fraction of TiC particles. As exhibited in Fig. 7a, the FeCrNiCu high-entropy alloy matrix is made up of a single FCC phase merely. Figure $7 \mathrm{~b}$ reveals that the $\mathrm{TiC}$ particles begins to form in the $5 \mathrm{vol} \% \mathrm{TiC} /$ $\mathrm{FeCrNiCu}$ high-entropy alloy matrix composites in comparison to the base alloy as seen in Fig. 7a. As the volume fraction of $\mathrm{TiC}$ particles gradually increase, its diffraction peak becomes more evident, as seen in Fig. 7c. According to Fig. $7 \mathrm{~d}$, a new peak of the $\mathrm{TiC}$ particles is found at $2 \theta \approx 60^{\circ}$, when the volume fraction of $\mathrm{TiC}$ particles increases to $15 \%$.

Figure $8 \mathrm{a}-\mathrm{d}$ show the microstructure of composites with different volume fractions of TiC particles. The EDS spectrum of composites is displayed in Fig. 8c, d. A single phase structure can be observed in Fig. 8a, suggesting that the matrix is only made of FCC phase, which is consistent with Fig. 7. The distribution of TiC particles in highentropy alloy matrix is shown in Fig. 8b, c. Compared to Fig. $8 \mathrm{c}$, the distribution of TiC particles becomes increasingly non-uniform as observed in Fig. 8d. The reason may be that the volume fraction is so large that the congregation of TiC particles occurs. Note that dark round phase in Fig. 8d represents TiC particles, whose average diameter is approximately $1.611 \mu \mathrm{m}$. Figure $8 \mathrm{c}$ indicates that the content of $\mathrm{Cu}$ 

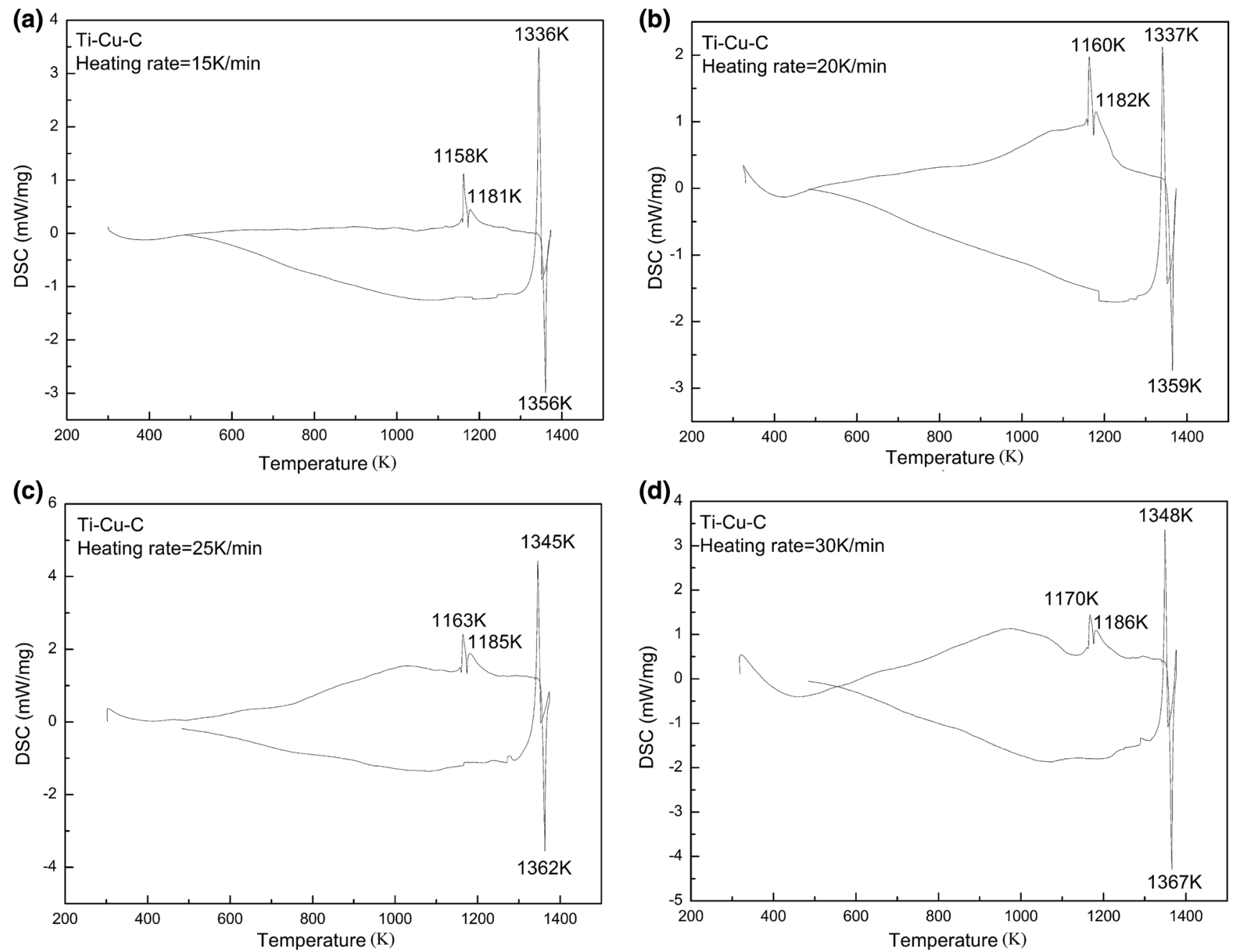

Fig. 5 DSC curves obtained at four different heating rates: a $15 \mathrm{~K} / \mathrm{min}$; b $20 \mathrm{~K} / \mathrm{min}$; (c) $25 \mathrm{~K} / \mathrm{min}$; (d) $30 \mathrm{~K} / \mathrm{min}$
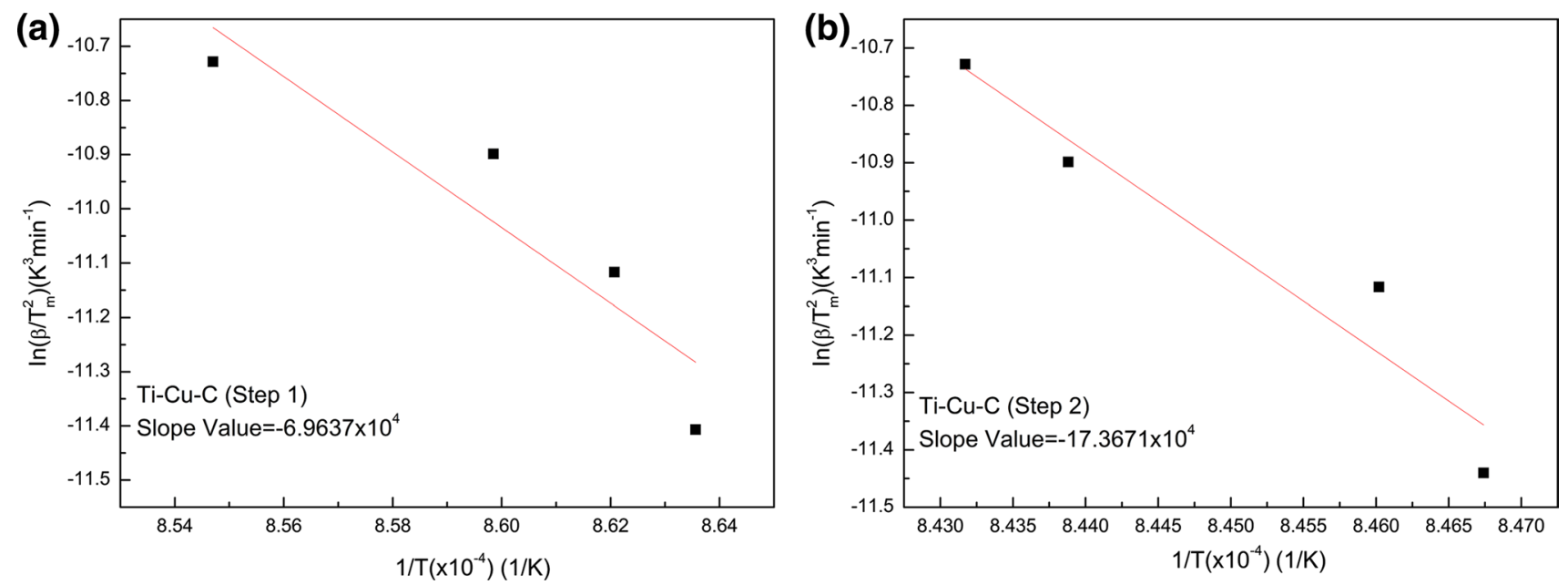

Fig. 6 Plots of the $\ln \left(\beta / T_{\mathrm{m}}{ }_{\mathrm{m}}\right)-1 / T_{\mathrm{m}}$ for the reactions occurring in the Ti-Cu-C system: a step 1 reaction and $\mathbf{b}$ step 2 reaction 

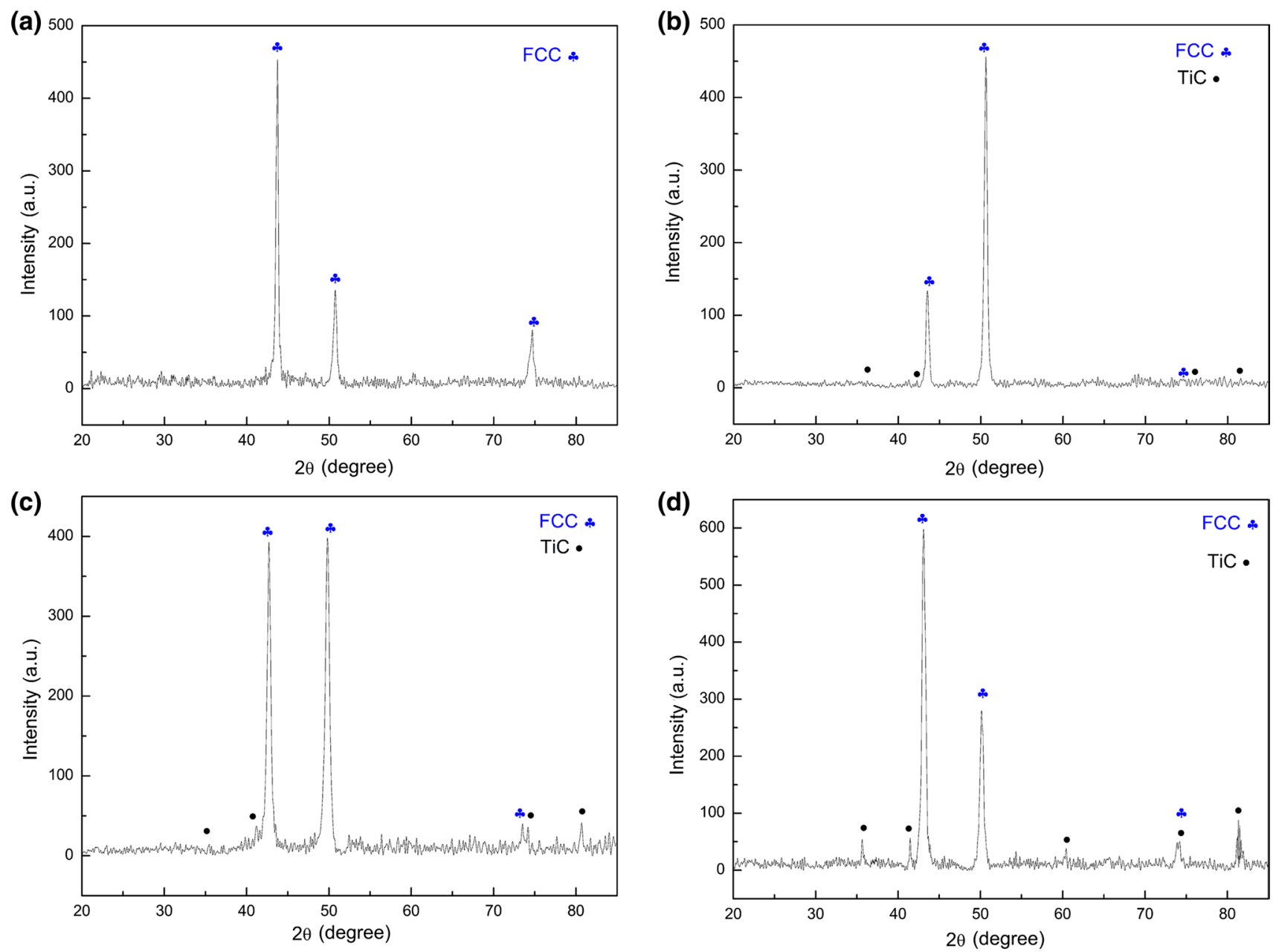

Fig. 7 XRD diffraction patterns of $\mathrm{FeCrNiCu}$ high-entropy alloy matrix composites with different volumes fractions of reinforcements: a matrix; b 5 vol\% TiC/HEA; c 10 vol\% TiC/HEA; d 15 vol\% TiC/HEA

in the matrix is relatively low, and the segregation of $\mathrm{Cu}$ may occur at the grain boundaries. The formation of these distinct regions may be explained by the difference in $\Delta H_{\text {mix }}$ value between $\mathrm{Cu}$ and other atoms [25, 26].

Figure 9a shows the microstructure of the $\mathrm{TiC} / \mathrm{FeCrNiCu}$ (10 vol\%) high-entropy alloy matrix composites. Apparently, the TiC particles have an irregular shape. The diffraction patterns of TiC particles are shown in Fig. 9b, and the corresponding crystal planes are indexed and lattice constants are derived.

\subsection{Mechanical Properties}

Figure 10 shows the hardness and engineering stress-strain curves of the high-entropy alloy matrix composites with different volume fractions of $\mathrm{TiC}$ particles. The mechanical properties of the base alloy and in situ composites are summarized in Table 1. As revealed in Table 1, the hardness of the composites increases by $126.9 \%$ from 351.4 to $797.3 \mathrm{HV}$ with the formation of in situ $\mathrm{TiC}$ particles. The engineering stress-strain curves of the alloy matrix and the new composites are shown in Fig. 10b. It is worth noting that HEAs have excellent mechanical properties compared to traditional alloys [27]. Apparently, with the increase in the volume fraction of $\mathrm{TiC}$, both the tensile yield strength and ultimate tensile strength increases markedly. The tensile yield strength of the high-entropy base alloy is $364.7 \mathrm{MPa}$. When the volume fraction of TiC increases from 5 to $15 \%$, the tensile strength of the composites increases from 425.6 to $605.1 \mathrm{MPa}$. Similarly, the ultimate tensile strength is enhanced as the volume fraction of $\mathrm{TiC}$ increases. The ultimate tensile strength of the matrix and composites (15\% vol TiC) are $565.5 \mathrm{MPa}$ and 769.2 MPa, respectively, representing an increase by $36.0 \%$. Nonetheless, the elongation of the composites decreases as a result of the increase in volume fraction of TiC. When the volume fraction of $\mathrm{TiC}$ increases from 0 to $15 \%$, the percent elongation decreases from 21.5 to $6.1 \%$. 

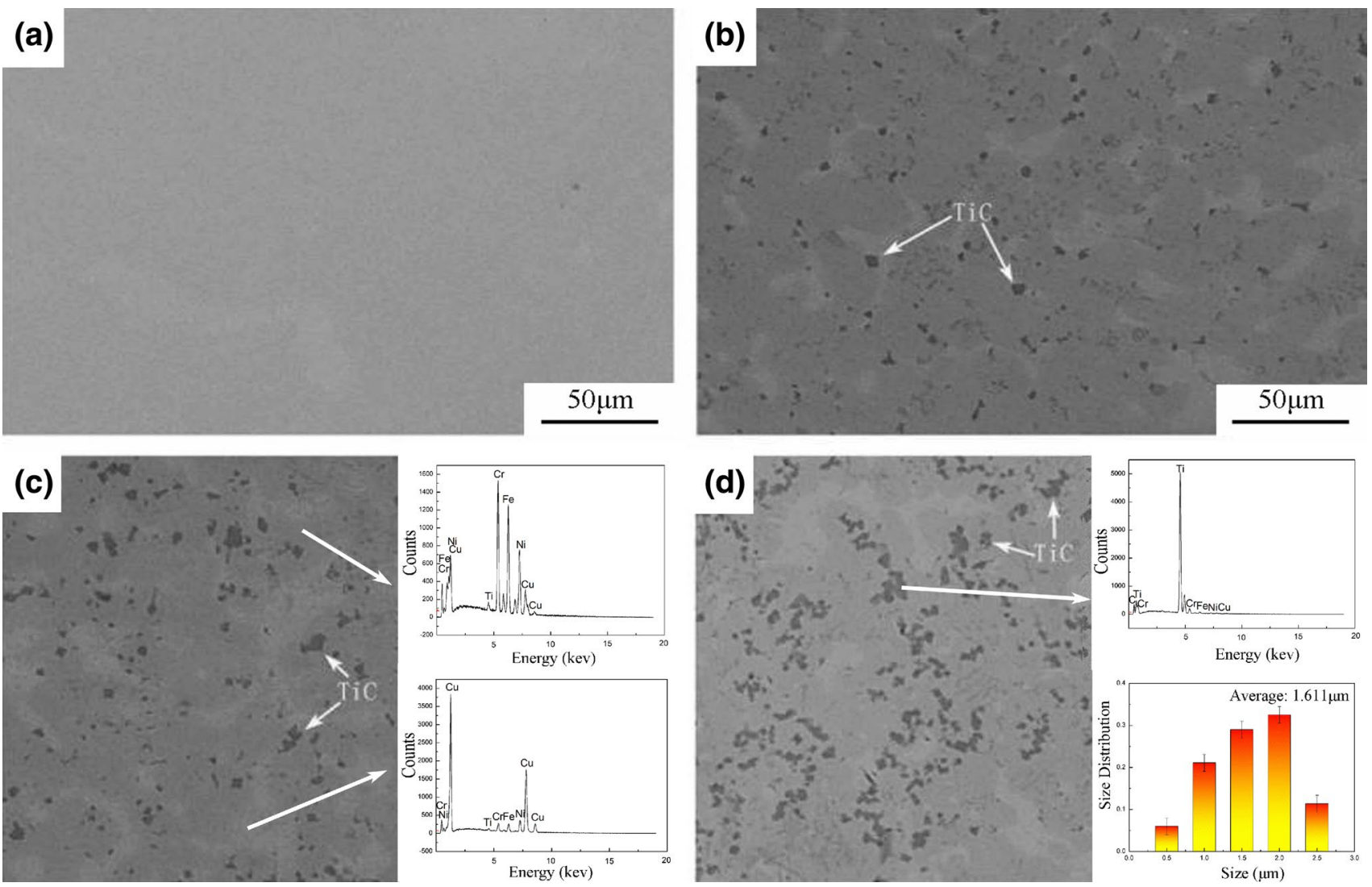

Fig. 8 SEM images and EDS spectra of the samples TiC/FeCrNiCu with different volumes fractions of reinforcements: a matrix; b 5 vol\% $\mathrm{TiC} /$ HEA; c 10 vol\% TiC/HEA; d 15 vol\% TiC/HEA
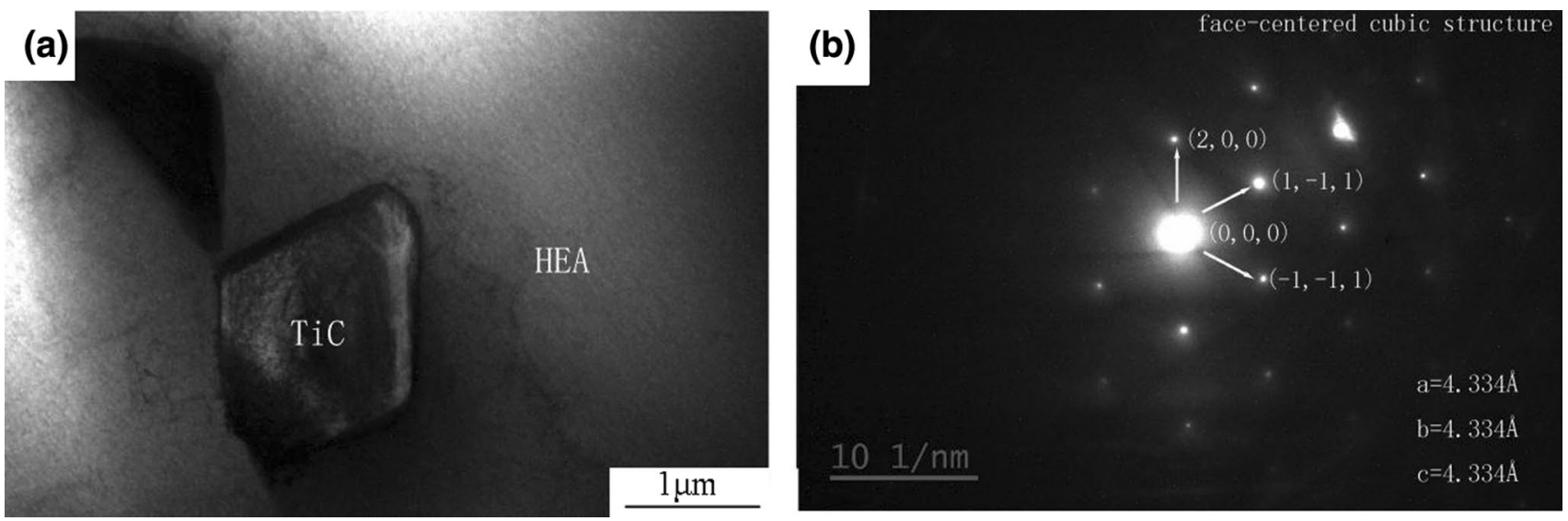

Fig. 9 a TEM micrograph of $\mathrm{TiC}$ in $10 \mathrm{vol} \% \mathrm{TiC} / \mathrm{FeCrNiCu}$ high-entropy alloy composites; b electron diffraction pattern of single TiC particle

Figure 11 reveals the fracture surface morphologies of the high-entropy alloy matrix composites with different volume fraction of $\mathrm{TiC}$ particles following the tensile tests. A large number of dimples shown in Fig. 11a reflect a good ductility [28]. Compared to the matrix, a small number of $\mathrm{TiC}$ particles were found in the fracture surface of the composite materials, as shown in Fig. 11b. In Fig. 11c, the number of dimple is reduced, but the fracture is still controlled by ductile process. It is inferred that the dimple is a plastic deformation caused by the interface modulation between the TiC particles and the high-entropy alloy matrix [29]. As the volume fraction of $\mathrm{TiC}$ increases to $15 \%$, river-like patterns 

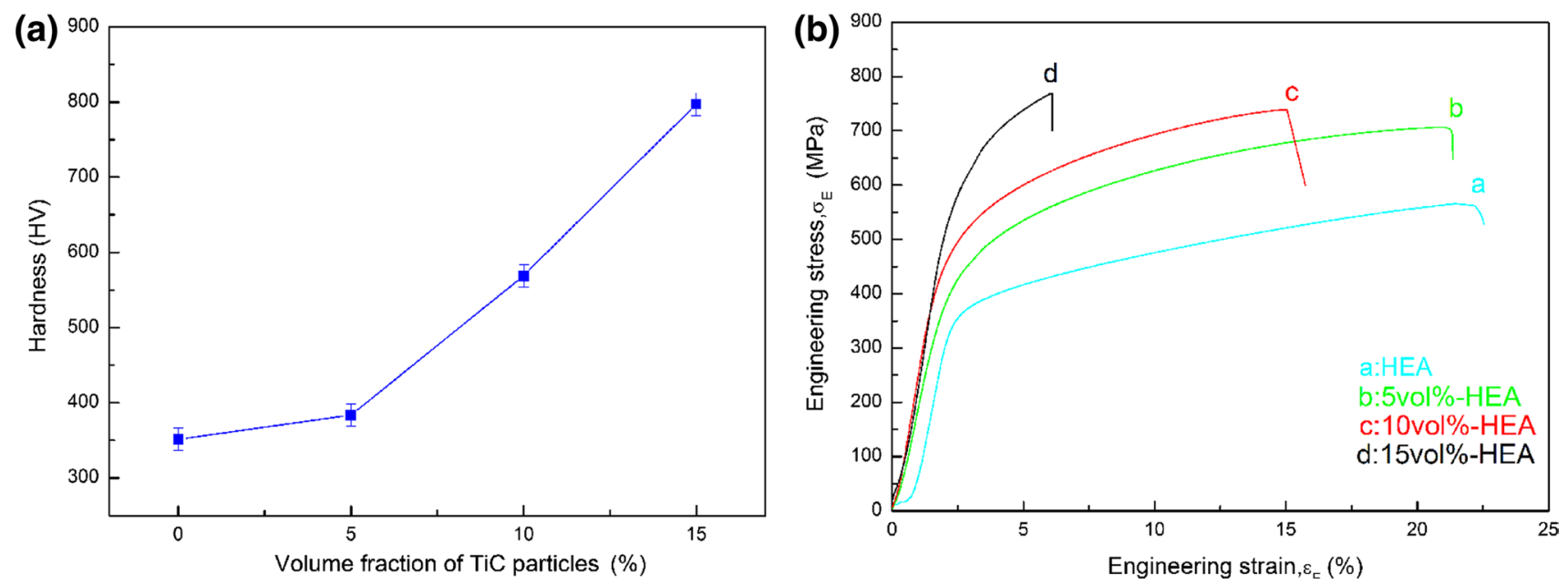

Fig. 10 a Hardness of samples with different volume fractions of reinforcements; $\mathbf{b}$ engineering stress-strain curves of samples with different volume fractions of reinforcements

Table 1 Mechanical properties of the $\mathrm{FeCrNiCu}$ high-entropy alloy with different volume fractions of in situ $\mathrm{TiC}$

\begin{tabular}{llllc}
\hline Sample & Hardness (HV) & $\begin{array}{l}\text { Yield strength } \\
(\mathrm{Mpa})\end{array}$ & $\begin{array}{l}\text { Ultimate strength } \\
(\mathrm{MPa})\end{array}$ & Elongation (\%) \\
\hline HEA & $351.4 \pm 15.3$ & 364.7 & 565.5 & 21.5 \\
5 vol\% TiC-HEA & $383.7 \pm 13.5$ & 425.6 & 706.5 & 21.0 \\
10 vol\% TiC-HEA & $569.1 \pm 14.1$ & 482.3 & 738.6 & 15.0 \\
15 vol\% TiC-HEA & $797.3 \pm 15.8$ & 605.1 & 769.2 & 6.1 \\
\hline
\end{tabular}

are evident in the fracture surface in Fig. 11d, which is a typical feature of brittle fracture [30].

Figure 12a shows the microstructure of the ex-situ composites. It can be seen that there are a number of $\mathrm{TiC}$ particles, with severe contamination at the interfaces with the matrix, which may be ascribed to the poor wettability of the interfaces $[18,19]$. The engineering stress-strain curves of both in situ and ex-situ composites at room temperature are displayed in Fig. 12b showing that the yield strength, ultimate tensile strength and elongation of in situ composites are superior to those of the ex-situ composites.

\subsection{Strengthening Mechanisms}

The hardness, tensile yield strength and ultimate tensile strength of high-entropy alloy matrix composites may be enhanced by several strengthening mechanisms: Orowan strengthening, dislocation strengthening, load-bearing effect and solid-solution strengthening mechanisms [31-34]. In this work, the Orowan strengthening, dislocation strengthening, load-bearing effect are deemed to be the main strengthening mechanism responsible for enhancing tensile yield strength of the high-entropy alloy matrix composites.

When TiC particles are small and dispersed in the matrix, the resulting strength is high, since the particles cannot be cut through by dislocations. As such, the applied load is mainly borne by the matrix. It can be explained by Orowan mechanism. The increase in tensile yield strength can be described by the Orowan-Ashby equation [35]:

$\Delta \sigma_{\text {Orowan }}=\frac{0.13 G_{\mathrm{m}} b}{\lambda} \ln \left(\frac{d}{2 b}\right)$,

where $G_{\mathrm{m}}$ is the shear modulus ( $102.4 \mathrm{GPa}$ [36]), $b$ is the Burgers coefficient which equal to $0.286 \mathrm{~nm}$ [37], $d$ is the average grain size of reinforcements, and $\lambda$ is the distance between the grains, which is defined as follows:

$\lambda=d\left(\left(\frac{1}{2 V_{\mathrm{P}}}\right)^{\frac{1}{3}}-1\right)$,

where $V_{\mathrm{P}}$ is the volume fraction of dispersed TiC particles. The dislocation slip in the matrix containing $\mathrm{TiC}$ particles would leave a dislocation ring around the particle, and with dislocations constantly passing through, the number of dislocation rings would increase. As such, the obstruction against the dislocation motion would increase, leading to enhanced strength.

Due to the difference in the thermal expansion coefficient between the matrix and the TiC particles, a certain 

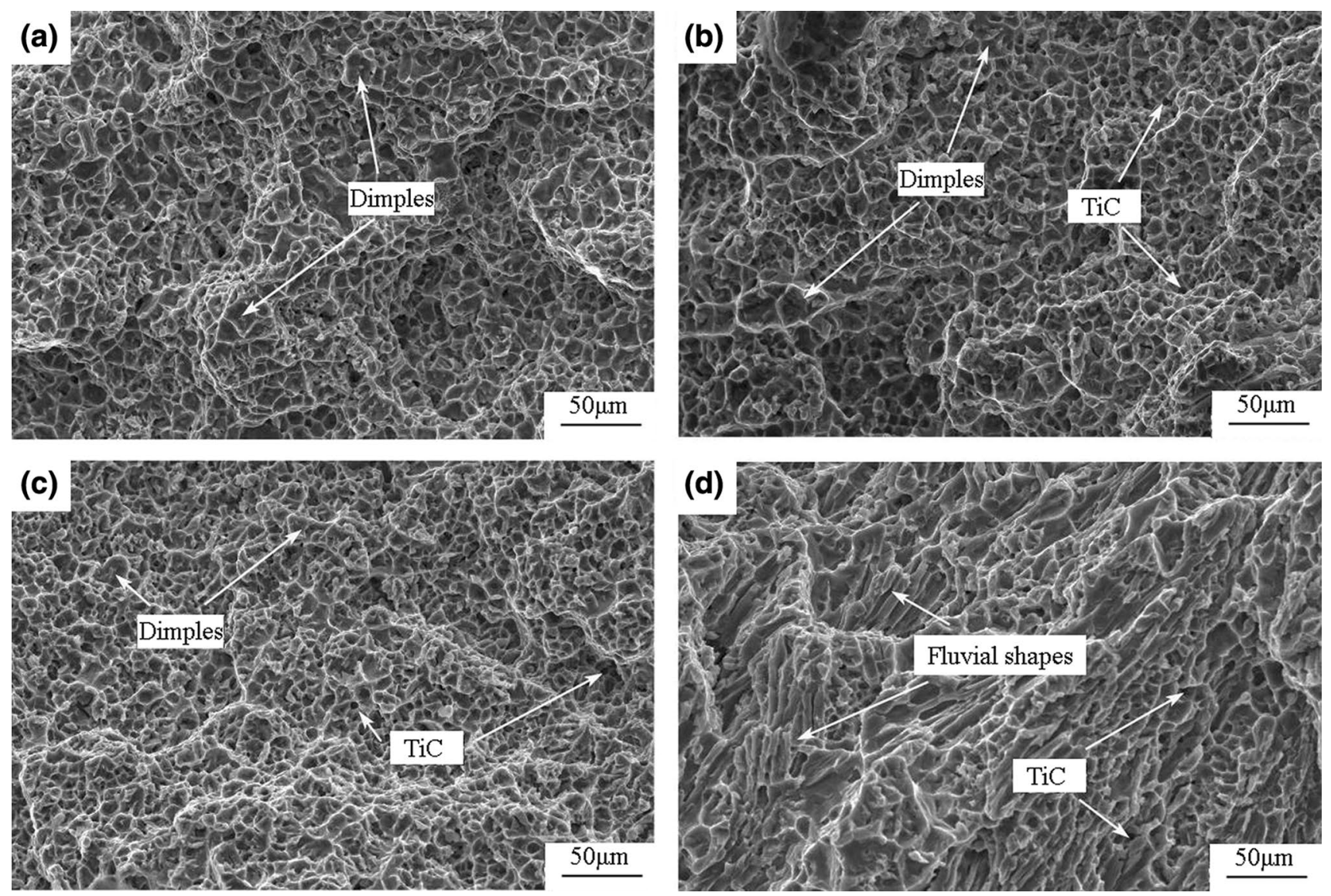

Fig. 11 Fracture surface of samples with different volume fractions of reinforcements: a matrix; b 5 vol\% TiC/HEA; c 10 vol\% TiC/HEA; d 15 vol\% TiC/HEA
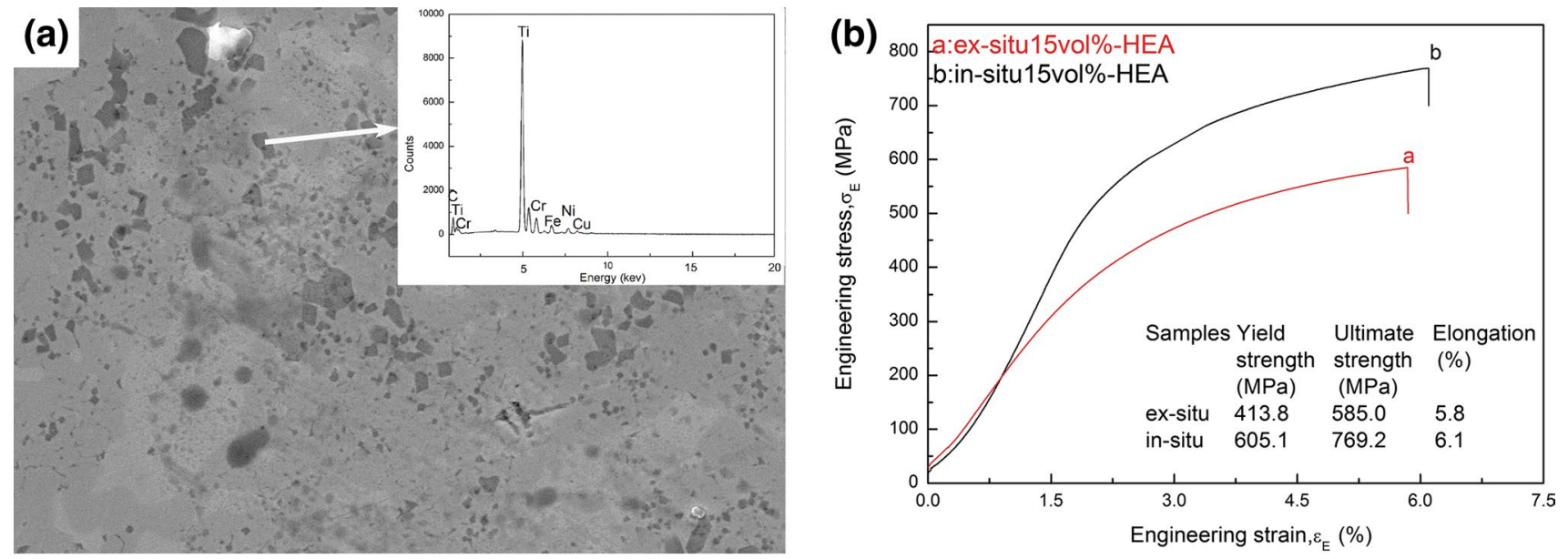

Fig. 12 a SEM image and EDS spectrum of the ex-situ $15 \% \mathrm{TiC} / \mathrm{FeCrNiCu}$ composite; $\mathbf{b}$ engineering stress-strain curves of samples with different preparation methods

number of dislocations would be induced around the TiC particles during the cooling stage, leading to an increase in the dislocation density and strength $[38,39]$. Moreover, plastic deformation can be generated in the matrix at the process of preparation to form a high-density dislocation, which results in dislocation strengthening [40, 41]. Dislocation 
strengthening is considered to be an important strengthening mechanism of high-entropy alloy matrix composites.

In addition, the effect of particle reinforcement should be taken into account. The tensile yield strength of the composites enhanced by the formation of $\mathrm{TiC}$ particles can be estimated by the following equation [42]:

$\Delta \sigma_{\text {load }}=0.5 f \sigma_{\mathrm{m}}$,

where $\sigma_{\mathrm{m}}$ is the tensile yield strength of high-entropy alloy matrix ( $364.7 \mathrm{MPa})$ and $f$ is the volume fraction of reinforcement. The $\mathrm{FeCrNiCu}$ high-entropy alloy matrix transfers some of the applied stress to TiC reinforcement, which bears a fraction of the load. As the volume fraction of reinforcement increases, the load of particle will increase as well.

\section{Conclusions}

TiC particle-reinforced $\mathrm{FeCrNiCu}$ high-entropy alloy matrix composites were prepared in situ by vacuum induction melting. The following conclusions can be drawn:

1 The reaction process of the $\mathrm{Ti}-\mathrm{Cu}-\mathrm{C}$ powder system consists of two consecutive steps: (a) $\mathrm{Cu}$ reacted with $\mathrm{Ti}$ to form $\mathrm{Cu}_{4} \mathrm{Ti}$ and then (b) $\mathrm{Cu}_{4} \mathrm{Ti}$ reacted with $\mathrm{C}$ to form $\mathrm{TiC}$ particles as reinforcement phase. The activation energies of the two reactions are found to be 578.7 $\mathrm{kJ} / \mathrm{mol}$ and $1443.2 \mathrm{~kJ} / \mathrm{mol}$, respectively.

2 The alloy matrix has a FCC structure. The TiC reinforcements are distributed in the matrix. The hardness, tensile yield strength and ultimate tensile strength of the $15 \mathrm{vol} \% \mathrm{TiC} / \mathrm{FeCrNiCu}$ composite are increased by $126.9 \%, 65.9 \%$ and $36.0 \%$, respectively. However, the elongation to failure is reduced from 21.5 to $6.1 \%$.

3 The strengthening is underpinned by the Orowan mechanism, dislocation strengthening and load-bearing effect, respectively.

Acknowledgements This work was financially supported by the National Natural Science Foundation of China (Nos. 51571118 and 51371098) and the Jiangsu Province Science and Technology Plan Project (No. BE2018753/KJ185629). Zong-Han Xie acknowledges the support of the Australian Research Council Discovery Projects.

\section{References}

[1] J.W. Yeh, S.K. Chen, S.J. Lin, J.Y. Gan, T.S. Chin, T.T. Sun, C.H. Tsau, S.Y. Chang, Adv. Eng. Mater. 6, 299 (2004)

[2] P.K. Huang, J.W. Yeh, T.T. Shun, S.K. Chen, Adv. Eng. Mater. 6, $74(2004)$

[3] Y.S. Huang, L. Chen, H.W. Lui, M.H. Cai, J.W. Yeh, Mater. Sci. Eng. A 457, 77 (2007)
[4] W.H. Liu, Y. Wu, J.Y. He, T.G. Nieh, Z.P. Lu, Scr. Mater. 68, 526 (2013)

[5] Y.P. Lu, X.Z. Gao, L. Jiang, Z.N. Chen, T.M. Wang, J.C. Jie, H.J. Kang, Y.B. Zhang, S. Guo, H.H. Ruan, Y.H. Zhao, Z.Q. Cao, T.J. Li, Acta Mater. 124, 143 (2017)

[6] B. Gludovatz, A. Hohenwarter, D. Catoor, E.H. Chang, E.P George, R.O. Ritchie, Science 345, 1153 (2014)

[7] Y.T. Wang, J.B. Li, Y.C. Xin, X.H. Chen, M. Rashad, B. Liu, Y. Liu, Acta Metall. Sin. (Engl. Lett.) 32, 932 (2019)

[8] G. Qin, R.R. Chen, H.T. Zheng, H.Z. Fang, L. Wang, Y.Q. Su, J.J. Guo, H.Z. Fu, J. Mater. Sci. Technol. 35, 578 (2019)

[9] K.F. Quiambao, S.J. McDonnell, D.K. Schreiber, A.Y. Gerard, K.M. Freedy, P. Lu, J.E. Saal, G.S. Frankel, J.R. Scully, Acta Mater. 164, 362 (2019)

[10] D.X. Qiao, H. Jiang, W.N. Jiao, Y.P. Lu, Z.Q. Cao, T.J. Li, Acta Metall. Sin. (Engl. Lett.) 32, 925 (2019)

[11] D. Yim, P. Sathiyamoorthi, S. Hong, H.S. Kim, J. Alloys Compd. 781, 389 (2019)

[12] X.D. Sun, H.G. Zhu, J.L. Li, J.W. Huang, Z.H. Xie, Mater. Sci. Eng. A 743, 540 (2019)

[13] H. Cheng, W. Chen, X.Q. Liu, Q.H. Tang, Y.C. Xie, P.Q. Dai, Mater. Sci. Eng. A 719, 192 (2018)

[14] Z.Z. Fu, R. Koc, Mater. Sci. Eng. A 702, 184 (2017)

[15] P. Wang, C. Gammer, F. Brenne, T. Niendorf, J. Eckert, S. Scudino, Compos. Part B 147, 162 (2018)

[16] Z. Szklarz, J. Lekki, P. Bobrowski, M.B. Szklarz, Ł. Rogal, Mater. Chem. Phys. 220, 449 (2018)

[17] Ł. Rogal, D. Kalita, A. Tarasek, P. Bobrowski, F. Czerwinski, J. Alloys Compd. 708, 344 (2017)

[18] N.N. Zhao, Y.H. Xu, Y.H. Fu, Surf. Coat. Technol. 309, 1105 (2017)

[19] X.F. Du, T. Gao, G.L. Liu, X.F. Liu, J. Alloys Compd. 695, 1 (2017)

[20] Y.H. Liang, H.Y. Wang, Y.F. Yang, Y.Y. Wang, Q.C. Jiang, J. Alloys Compd. 452, 298 (2008)

[21] R. Arroyave, T.W. Eagar, L. Kaufman, J. Alloys Compd. 351, 158 (2003)

[22] Z.L. Yu, H.G. Zhu, J.W. Huang, J.L. Li, Z.H. Xie, Powder Technol. 320, 66 (2017)

[23] F.L. Wang, Y.P. Li, K. Wakoh, Y. Koizumi, Mater. Des. 61, 70 (2014)

[24] R.L. Blaine, H.E. Kissinger, Thermochim. Acta 540(14), 1 (2012)

[25] A. Takeuchi, A. Inoue, Mater. Trans. 46, 2817 (2005)

[26] X.G. Yang, Y. Zhou, R.H. Zhu, S.Q. Xi, C. He, H.J. Wu, Y. Gao, Acta Metall. Sin. (Engl. Lett.) (2019). https://doi.org/10.1007/ s40195-019-00977-1

[27] Y.F. Wang, S.G. Ma, X.H. Chen, J.Y. Shi, Y. Zhang, J.W. Qiao, Acta Metall. Sin. (Engl. Lett.) 26, 277 (2013)

[28] Y.X. Zhang, W.J. Liu, P.F. Xing, F. Wang, J.C. He, Acta Metall. Sin. (Engl. Lett.) 25, 124 (2012)

[29] H. Zhang, H. Zhu, J. Huang, J.L. Li, Z.H. Xie, Mater. Sci. Eng. A 719, $140(2018)$

[30] C. Xiang, Z.M. Zhang, H.M. Fu, E.H. Han, J.Q. Wang, H.F. Zhang, G.D. Hu, Acta Metall. Sin. (Engl. Lett.) 32, 1053 (2019)

[31] Y. Zhang, X. Wang, J. Li, Y. Huang, Y. Lu, X. Sun, Mater. Sci. Eng. A 724, 148 (2018)

[32] F. Saba, F.M. Zhang, S.L. Liu, T.F. Liu, Compos. Part B 167, 7 (2019)

[33] J.Y. He, H. Wang, H.L. Huang, X.D. Xu, M.W. Chen, Y. Wu, X.J. Liu, T.G. Nieh, Acta Mater. 102, 187 (2016)

[34] P.F. Zhou, D.H. Xiao, T.C. Yuan, Acta Metall. Sin. (Engl. Lett.) (2019). https://doi.org/10.1007/s40195-019-00962-8

[35] Z. Zhang, D.L. Chen, Scr. Mater. 54, 1321 (2006)

[36] H. Wu, S.R. Huang, C.Y. Zhu, H.G. Zhu, Z.H. Xie, Prog. Nat. Sci. Mater. Int. (2020). https://doi.org/10.1016/j.pnsc.2020.01.012 
[37] H. Li, X.M. Wang, L.H. Chai, H.J. Wang, Z.Y. Chen, Z.L. Xiang, T.N. Jin, Mater. Sci. Eng. A 720, 60 (2018)

[38] X.D. Sun, H.G. Zhu, J.L. Li, J.W. Huang, Z.H. Xie, Mater. Chem. Phys. 220, 449 (2018)

[39] D.B. Miraclea, O.N. Senkov, Acta Mater. 122, 448 (2017)
[40] R.J. Arsenault, N. Shi, Mater. Sci. Eng. 81, 175 (1986)

[41] Z. Zhang, D.L. Chen, Mater. Sci. Eng. A 483-484, 148 (2008)

[42] C. Cai, S. He, L.F. Li, Q. Teng, B. Song, C.Z. Yan, Q.S. Wei, Y.S. Shi, Compos. Part B 164, 546 (2019) 